\title{
Maternal and perinatal outcome in pregnant women with hypertensive disorders: a population-based study
}

\author{
S. Shruthi, G. Thenmozhi* \\ Department of Obstetrics and Gynecology, Government Chengalpattu Medical College and Hospital Chengalpattu, \\ India \\ Received: 16 October 2019 \\ Revised: 26 November 2019 \\ Accepted: 02 December 2019 \\ *Correspondence: \\ Dr. G. Thenmozhi, \\ E-mail: drthenmozhi135@gmail.com \\ Copyright: (c) the author(s), publisher and licensee Medip Academy. This is an open-access article distributed under \\ the terms of the Creative Commons Attribution Non-Commercial License, which permits unrestricted non-commercial \\ use, distribution, and reproduction in any medium, provided the original work is properly cited.
}

\begin{abstract}
Background: Hypertension during pregnancy is one of the well-known complications of dating from ancient times. It remains as one of the leading causes of maternal mortality and morbidity through its myriad complications. To study the risk factors, prevalence and epidemiological parameters of antenatal mothers presenting with hypertension during pregnancy.

Methods: This study was on hypertensive disorders of pregnancy including mild, severe preeclampsia, eclampsia, and chronic hypertension at Chengalpattu Medical College Hospital, Chengalpattu in a period of $1^{\text {st }}$ year from October 2016 to September 2017.

Results: Out of 450 hypertensive pregnancies, the majority were severe preeclampsia (39.6\%). There were 78 women with gestational hypertension $(17.3 \%), 125$ women with mild preeclampsia $(27.8 \%)$, 178 women with severe preeclampsia (39.6\%), 64 women with eclampsia out of which 52 were AP eclampsia (11.6\%), 1 case was IP eclampsia (0.2\%) and 11 women were PP eclampsia (2.4\%). 5 women were chronic hypertensives $(1.1 \%)$

Conclusions: Complications can affect all maternal systems including central nervous system, renal system, and hematological systems. Apart from these, the fetus also faces the brunt of insult. Fetal complications include prematurity, low birth weight, stillbirths, intrauterine deaths, and intrauterine growth restrictions. However, such vast complications can be prevented by simple blood pressure monitoring and proper antenatal mother follow-up.
\end{abstract}

Keywords: Gestational hypertension, Hypertensive disorders, Pregnancy, Prematurity

\section{INTRODUCTION}

Hypertension during pregnancy is one of the well-known complications of dating from ancient times. It remains as one of the leading causes of maternal mortality and morbidity through its myriad complications. ${ }^{1}$ This common medical disorder of pregnancy represents about 7 to $15 \%$ of all pregnancies and accounts for nearly $25 \%$ of admissions in antenatal wards and hypertensive disorders account for $16 \%$ of maternal mortality worldwide, according to the WHO analysis of causes of maternal death. ${ }^{2}$ Of the studies conducted in India, the prevalence of gestational hypertension was found to be about $7.8 \%$. However, this figure is increasing as women postpone their first pregnancy and also because of increasing metabolic complications like obesity. But, the incidence of complications is decreasing in developed nations due to better antenatal services. ${ }^{3}$ Apart from the various deleterious antenatal complications, pregnancyinduced hypertension also poses a life-long risk for the woman by transforming itself into chronic hypertension and also by increasing the woman's cardiovascular risk. 
Hypertension during pregnancy along with proteinuria also adversely affects the neonate's health by being the leading cause of stillbirth, fetal growth restriction, low birth weight and admissions to neonatal intensive care units. ${ }^{4}$ For a disorder with such vast implications, it is a relatively easier condition to diagnose provided a woman is given proper antenatal care and blood pressure monitoring. Hence, the importance of studying this disorder in great lengths arises. ${ }^{5}$

\section{METHODS}

This study was undertaken to evaluate the maternal and perinatal outcomes throughout the spectrum of hypertensive disorders of pregnancy including mild, severe preeclampsia, eclampsia, and chronic hypertension at Chengalpattu Medical College Hospital, Chengalpattu in a period of $1^{\text {st }}$ year from October 2016 to September 2017. Totally 450 Pregnant Women were included in the Study who are attending the department of obstetrics and gynaecology, Chengalpattu Medical College, Chengalpattu.

\section{Inclusion criteria}

- All pregnant women diagnosed with pregnancyinduced hypertension based on the criteria defined by the working of the NHBPEP (National high blood pressure education program)

- Gestational hypertension or pregnancy-induced hypertension.

- Pre-eclampsia- eclampsia

- Chronic hypertension

- Preeclampsia superimposed on chronic hypertension.

\section{Exclusion criteria}

- Multiple pregnancy

- Major fetal anomaly, incompatible with survival

- Patients who were diagnosed with other causes of convulsions in pregnancy like cerebral malaria and epilepsy

- Pregnancies complicated with diabetes mellitus, primary renal disease, and collagen vascular diseases.

\section{Study maneuver}

All the pregnant women coming to the antenatal OPD and obstetric casualty were screened for hypertension and its complications. Blood pressure was measured in the sitting position in the right upper limb using mercury sphygmomanometer with the arm at the level of the heart. An appropriate bladder cuff was used which encircles two-thirds of the arm. Blood pressure value of more than $140 / 90 \mathrm{mmHg}$ was followed up with another reading at an interval of 6 hours. The diagnosis was based on NHBPEP guidelines. After carefully considering the inclusion and exclusion criteria, 450 women were selected for the study and were followed up throughout their gestation and until 2 weeks post-delivery. Though patients were hospitalized in majority of cases, in selected cases (gestational hypertension, mild preeclampsia, chronic hypertension with regular blood pressure measurements) at the request of the patient, ambulatory control was allowed. Demographic data needed for the study such as age, parity, socioeconomic status, booking status, and residential area were collected by careful history taking. These along with the clinical data, laboratory results, delivery details, and maternal and fetal outcomes were made note of in the pre-tested checklist proforma. On admission, a thorough clinical examination was made including general physical examination, build, nutritional status, height, weight, BMI, blood pressure and pulse along with presence or absence of pallor and pedal edema. Weight gain during pregnancy was noted. CVS and RS were examined. Abdominal examination was done to determine the uterine height (in weeks), fetal lie, presentation, and fetal heart rate. Blood pressure monitoring was done twice daily for all patients with more frequent measurements ( $4^{\text {th }}$ hourly) for those with elevated blood pressure. Daily urine albumin was monitored with the help of dipsticks supported by laboratory urine analyses. The patients were watched for the presence of symptoms of severe preeclampsia such as severe headache, blurring of vision, oliguria and epigastric pain. Based on all these data, patients were classified into one of the following five classes of hypertension based on NHBPEP guidelines: blood was collected and sent for investigations such as complete blood hemogram, liver function tests, renal function tests, and serum uric acid. Urine was sent for urine albumin and sugar determination for all patients. Other investigations include coagulation profile, bleeding and clotting time, ECG, 24-hour urinary protein.

\section{Statistical analysis}

For statistical analysis, the chi-square test was used, with a p-value of less than 0.05 considered significant. The $95 \%$ confidence intervals were calculated with a statistical computer program and interpreted as the range of values that has a $95 \%$ chance of including the true values.

\section{RESULTS}

Table 1 shows the median gestational ages for perinatal deaths and survivors in women with preeclampsia were 32 and 38 weeks, respectively. In eclamptic women, however, the median gestational ages for perinatal deaths and survivors were term ( 37 versus 38 weeks).

Table 2 shows the women with hypertension, 1411 $(0.6 \%)$ had chronic hypertension, 10379 (4.2\%) preeclampsia, $731(0.3 \%)$ chronic hypertension with superimposed pre-eclampsia, 10864 (4.3\%) gestational hypertension and $1132(0.5 \%)$ hypertension of unspecified type. One hundred and sixty-one women 
$(0.064 \%)$ were reported to have eclampsia. Women with chronic hypertension (with or without pre-eclampsia) were older, on average, than women without hypertension, while those with pre-eclampsia or gestational hypertension had a similar age distribution to women without hypertension. The proportion of nulliparous women also varied by hypertension type. Compared with women who did not have hypertension.

Table 1: Age distribution in types of hypertension.

\begin{tabular}{|lllllll|}
\hline Age in years & Gestational HT & Preeclampsia & Severe preeclampsia & Eclampsia & Chronic HT & Total \\
\hline$<=20$ & 13 & 24 & 38 & 20 & 0 & $95(21.1 \%)$ \\
\hline $21-25$ & 46 & 67 & 88 & 32 & 0 & $233(51.7 \%)$ \\
\hline $26-30$ & 16 & 30 & 44 & 11 & 2 & $103(22.9 \%)$ \\
\hline $31-35$ & 3 & 2 & 7 & 1 & 3 & $16(3.6 \%)$ \\
\hline$>=36$ & 0 & 2 & 1 & 0 & 0 & $3(0.7 \%)$ \\
\hline Total & $\mathbf{7 8}$ & $\mathbf{1 2 5}$ & $\mathbf{1 7 8}$ & $\mathbf{6 4}$ & $\mathbf{5}$ & $\mathbf{4 5 0}$ \\
\hline
\end{tabular}

Table 2: Types of hypertension.

\begin{tabular}{|lll|}
\hline Type of hypertension & No. of patients & Percentage \\
\hline Gestational HT & 78 & $17.3 \%$ \\
\hline Mild preeclampsia & 125 & $27.8 \%$ \\
\hline Severe preeclampsia & 178 & $39.6 \%$ \\
\hline AP eclampsia & 52 & $11.6 \%$ \\
\hline IP eclampsia & 1 & $0.2 \%$ \\
\hline PP eclampsia & 11 & $2.4 \%$ \\
\hline Chronic HT & 5 & $1.1 \%$ \\
\hline Total & $\mathbf{4 5 0}$ & $\mathbf{1 0 0 \%}$ \\
\hline
\end{tabular}

Table 3: Gravida status in hypertensive types.

\begin{tabular}{|lllllll|}
\hline Gravida & Gestational HT & Preeclampsia & Severe PE & Eclampsia & Chronic HT & Total \\
\hline Primi & $43(55.1 \%)$ & $71(56.8 \%)$ & $113(63.5 \%)$ & $45(70.3 \%)$ & $1(20 \%)$ & $273(60.7 \%)$ \\
\hline G2 & $25(32.1 \%)$ & $39(31.2 \%)$ & $42(23.6 \%)$ & $15(23.4 \%)$ & $2(40 \%)$ & $123(27.3 \%)$ \\
\hline G3 and above & $10(12.8 \%)$ & $15(12 \%)$ & $23(12.9 \%)$ & $4(6.3 \%)$ & $2(40 \%)$ & $54(12 \%)$ \\
\hline Total & $\mathbf{7 8}$ & $\mathbf{1 2 5}$ & $\mathbf{1 7 8}$ & $\mathbf{6 4}$ & $\mathbf{5}$ & $\mathbf{4 5 0}$ \\
\hline
\end{tabular}

Table 4: Gestational age at delivery.

\begin{tabular}{|llllllll|}
\hline $\begin{array}{l}\text { Gestational } \\
\text { age }\end{array}$ & $\begin{array}{l}\text { Gestational } \\
\text { HT }\end{array}$ & Preeclampsia & Severe PE & AP eclampsia & $\begin{array}{l}\text { PP and IP } \\
\text { eclampsia }\end{array}$ & $\begin{array}{l}\text { Chronic } \\
\text { HT }\end{array}$ & Total \\
\hline$<=28$ & 0 & 0 & $21(11.8 \%)$ & $3(5.8 \%)$ & 0 & 0 & $24(53.3 \%)$ \\
\hline $29-34$ & 0 & 0 & $31(17.4 \%)$ & $17(32.7 \%)$ & 0 & 0 & $46(10.2 \%)$ \\
\hline $35-37$ & $6(7.7 \%)$ & $19(15.2 \%)$ & $84(47.2 \%)$ & $18(34.6 \%)$ & $6(50 \%)$ & $3(60 \%)$ & $91(20.2 \%)$ \\
\hline$>37$ & $72(92.3 \%)$ & $106(84.8 \%)$ & $42(23.6 \%)$ & $14(26.9 \%)$ & $6(50 \%)$ & $2(40 \%)$ & $289(64.2 \%)$ \\
\hline Total & $\mathbf{7 8}$ & $\mathbf{1 2 5}$ & $\mathbf{1 7 8}$ & $\mathbf{5 2}$ & $\mathbf{1 2}$ & $\mathbf{5}$ & $\mathbf{4 5 0}$ \\
\hline
\end{tabular}

Table 3, of the total participants, 450 were primigravida and $87.6 \%$ had at least one ANC contact. The proportion of preterm delivery was $28.1 \%$ whereas low birth weight was $9.8 \%$. A total of $47(30.7 \%)$ had Systolic Blood Pressure of $160 \mathrm{mmhg}$ or more and $38(24.8 \%)$ of them had Diastolic Blood Pressure of $110 \mathrm{mmhg}$ or more. The prevalence of severe preeclampsia, eclampsia, mild preeclampsia and super imposed preeclampsia.
Table 4, the mean EGA at delivery was 37 weeks 2 days (standard deviation, 3 weeks 5 days). About $38 \%$ of live births had low Apgar scores of $<7$ in the first minute. The prevalence of low Apgar scores improved significantly to $9.7 \%$ after 5 minutes $(37.8 \%$ versus $9.7 \%$; p <0.001). Nearly 4 out of 10 new-borns $(37.6 \%)$ were low birth weight. The mean birth weight was $2.6 \mathrm{~kg}$ (standard deviation, $0.84 \mathrm{~kg}$ ). About one quarter (26.2\%) of the new-borns were admitted to NICU. Altogether, there were $84(18.8 \%)$ abortions/perinatal deaths with 51 
(11.4\%) being stillbirths (in-utero fetal demise after 28 completed weeks). Two-thirds (34) of the stillbirths occurred prior to onset of labour and the remaining third (17) died during labour and delivery. Overall, $87 \%$ of the women had adverse maternal or fetal outcomes.

Table 5, the total percentages for the standard vaginal mode of delivery are as follows: $47.59 \%$ of mothers with pregnancy-induced hypertension, $35.34 \%$ of mothers with preeclampsia, $39.64 \%$ of mothers with eclampsia, and $68 \%$ of mothers with generalized hypertension delivered by standard vaginal delivery. The total percentages for the cesarean mode of delivery are as follows: $45.78 \%$ of mothers with pregnancy-induced hypertension, $57.89 \%$ of mothers with preeclampsia, $44.10 \%$ of mothers with eclampsia, and $28 \%$ of mothers with generalized hypertension delivered by cesarean section. The total percentages for the assisted vaginal mode of delivery are as follows: $0.90 \%$ of mothers with pregnancy-induced hypertension, $3.01 \%$ of mothers with preeclampsia, $2.90 \%$ of mothers with eclampsia, and $4 \%$ of mothers with generalized hypertension delivered by assisted vaginal delivery.

Table 5: Mode of delivery in hypertension types.

\begin{tabular}{|lllllll|}
\hline Mode of delivery & Gestational HT & Preeclampsia & Severe PE & Eclampsia & Chronic HT & Total \\
\hline Labour natural & $37(47.4 \%)$ & $61(48.8 \%)$ & $63(35.3 \%)$ & $15(23.4 \%)$ & $1(20 \%)$ & $177(39.3 \%)$ \\
\hline Assisted delivery & $9(11.5 \%)$ & $11(8.8 \%)$ & 0 & 0 & 0 & $20(4.4 \%)$ \\
\hline Hysterotomy & 0 & 0 & 0 & $4(6.2 \%)$ & 0 & $4(0.9 \%)$ \\
\hline Spontaneous expulsion & 0 & 0 & $21(11.8 \%)$ & $3(4.7 \%)$ & 0 & $24(5.4 \%)$ \\
\hline LSCS & $32(41.1 \%)$ & $53(42.4 \%)$ & $94(52.9 \%)$ & $42(65.7 \%)$ & $4(80 \%)$ & $225(50 \%)$ \\
\hline Total & $\mathbf{7 8}$ & $\mathbf{1 2 5}$ & $\mathbf{1 7 8}$ & $\mathbf{6 4}$ & $\mathbf{5}$ & $\mathbf{4 5 0}$ \\
\hline
\end{tabular}

Table 6: Maternal complications in hypertension types.

\begin{tabular}{|lllllll|}
\hline Maternal complications & Gestational HT & Preeclampsia & Severe PE & Eclampsia & Chronic HT & Total \\
\hline Maternal death & 0 & 0 & 1 & 2 & 0 & $3(0.6 \%)$ \\
\hline ARF & 0 & 0 & 2 & 4 & 0 & $6(1.3 \%)$ \\
\hline Abruptio placenta & 0 & 9 & 37 & 5 & 0 & $51(11.3 \%)$ \\
\hline DIC & 0 & 0 & 6 & 1 & 0 & $7(1.6 \%)$ \\
\hline CVA & 0 & 0 & 0 & 9 & 0 & $9(2 \%)$ \\
\hline HELLP & 0 & 0 & 6 & 2 & 0 & $8(1.8 \%)$ \\
\hline PPH & 1 & 6 & 19 & 1 & 0 & $27(6 \%)$ \\
\hline Pulmonary edema & 0 & 0 & 1 & 1 & 0 & $2(0.4 \%)$ \\
\hline Retinopathy & 0 & 0 & 1 & 0 & 0 & $1(0.2 \%)$ \\
\hline Total & $\mathbf{1}$ & $\mathbf{1 5}$ & $\mathbf{7 3}$ & $\mathbf{2 5}$ & $\mathbf{0}$ & $\mathbf{1 1 4}$ \\
\hline
\end{tabular}

Table 7: Postpartum return of blood pressure to baseline.

\begin{tabular}{|llll|}
\hline Hypertension type & $\mathbf{0 - 2}$ days & $\mathbf{3 - 1 3}$ days & 2 weeks and above \\
\hline Gestational HT & 75 & 3 & - \\
\hline Preeclampsia & 102 & 14 & 7 \\
\hline Severe preeclampsia & 8 & 92 & 57 \\
\hline Eclampsia & - & 29 & 27 \\
\hline Total & $\mathbf{1 8 5}(\mathbf{4 1 . 1})$ & $\mathbf{1 3 8}(\mathbf{2 0 . 7 )}$ & $\mathbf{9 1}(\mathbf{2 0 . 2})$ \\
\hline
\end{tabular}

Table 6, one case was diagnosed as HELLP syndrome that was nulliparus, in age group 18-35 years and 28-37 weeks of gestational age. From 22 eclamptic cases, 2 cases were more than 35 years old $(9.1 \%), 3$ cases were less than 18 years old (13.6\%) and the others (17 cases) were between 18 and 35 years old $(p=0.351)$. All the eclamptic seizures occurred in ante partum period. From the 17 cases with hepatic complications only, 1 case $(0 / 3 \%)$ diagnosed with hematoma. Of 13 cases with
Visual disturbances, 5 cases $(1 / 4 \%)$ involved retinopathy grade II and III and the rest had reduced visual acuity.

Table 7, Most babies born to mothers with any documented maternal hypertensive did not have any complication (84\%). However, among those babies with complications, the most prevalent complication among those born to mothers with any documented maternal hypertensive disorder is intrauterine fetal death (4\%). 
Other prevalent baby complications among this population are fetal distress (3\%), prematurity (3\%).

Table 8 outlines baby outcome by maternal hypertensive disorder status. The status is documented as either alive at discharge, dead at discharge (stillbirths and live births), or unknown. The percentage of deaths varied by complication For babies documented as alive at discharge, $85.41 \%$ had a perinatal death for mothers with no complication, $58.09 \%$ had death for mothers with pregnancy induced hypertension, $61.15 \%$ had death for mothers with mothers with preeclampsia, $50.22 \%$ had death for mothers with mothers with eclampsia, and $61.54 \%$ had death for mothers with generalized/unspecified hypertension. For babies documented as dead at discharge, $1.88 \%$ had death for mothers with no complication, $19.49 \%$ had death for mothers with pregnancy-induced hypertension, $22.3 \%$ had death for mothers with preeclampsia, $20.69 \%$ had death for mothers with eclampsia, and $15.38 \%$ had death for mothers with generalized/unspecified hypertension.

Table 8: Fetal complications in hypertension types.

\begin{tabular}{|lllllll|}
\hline Fetal complications & Gestational HT & Preeclampsia & Severe PE & Eclampsia & Chronic HT & Total \\
\hline Neonatal death & 0 & 2 & 9 & 5 & 0 & $16(3.5 \%)$ \\
\hline Stillbirth & 0 & 0 & 2 & 0 & 0 & $2(0.4 \%)$ \\
\hline Prematurity & 6 & 19 & 93 & 20 & 1 & $139(30.9 \%)$ \\
\hline IUD & 0 & 0 & 21 & 4 & 0 & $25(5.5 \%)$ \\
\hline IUGR & 4 & 22 & 37 & 9 & 0 & $72(16 \%)$ \\
\hline Birth asphyxia & 0 & 3 & 9 & 5 & 0 & $17(3.8 \%)$ \\
\hline Total & $\mathbf{1 0}$ & $\mathbf{4 6}$ & $\mathbf{1 7 1}$ & $\mathbf{4 3}$ & $\mathbf{1}$ & $\mathbf{2 7 1}$ \\
\hline
\end{tabular}

\section{DISCUSSION}

Significantly increased risk of perinatal mortality among babies with low gestational age and low birth weight in this study is consistent with several other studies. The finding of a strong association of perinatal mortality with low gestational age and low birth weight is probably in line with the increased risk of perinatal mortality among babies with antepartum onset of HDP. ${ }^{6}$ It was observed that nearly three-fourths of the perinatal deaths $(71 \%)$ in women with antepartum onset of HDP were either preterm or very preterm at birth. The implication is that HDP has probably exposed several babies to premature delivery and its complications. The previous study also reported the increased risk of premature delivery in women with HDP. ${ }^{7}$ The exact incidence of hypertensive disorders complicating pregnancy could not be determined by the study since the exclusion criteria of the study ruled out multiple pregnancies, pregnancies with other comorbidities such as diabetes mellitus, renal disorders and so on. ${ }^{8}$ Of the 450 women in our study, the most common hypertension type was severe preeclampsia with an incidence of $39.6 \%$ while the next common was mild preeclampsia with an incidence of $27.8 \%$. Similar findings were reported by Jeffcoate et al in whose study severe preeclampsia was the most common with an incidence of $35.5 \%$. However, this was followed by eclampsia (19\%) and then by Mild Preeclampsia (14.9\%). The proportion of eclampsia in the study is $14.2 \%{ }^{9}$ However in our study, chronic hypertension constituted only $1.1 \%$ of all cases. This discrepancy might be due to the fact that the presence of other comorbidities has been already ruled out and hence the figure of women with pure hypertension alone dips It has been traditionally said that Preeclampsia is a disease of primiparity. Conforming to the same, primigravida constituted $60.7 \%$ of all hypertensive mothers in our study. The next majority was the second gravida making up $27.3 \%$ while higher parity makes up the rest $(12 \%) .{ }^{10}$ LSCS was the common mode of termination of the pregnancy (in $50 \%$ of cases) closely followed by labour natural (in 39.3\%). Assisted delivery in the form of forceps, vacuum, etc. was resorted to in $4.4 \%$ of cases. ${ }^{11}$ This correlates well with the Indian study conducted by Levine RJ et al, where abdominal route (including both LSCS and hysterotomy) was the common method of terminating hypertensive pregnancies with a slightly higher incidence than in our study $(65.6 \%)$. Vaginal delivery constituted about $34.4 \%$ in their study while this was slightly higher $(39.3 \%)$ in our study. ${ }^{12}$ The most common maternal complication noted in our study was that of placental abruption (11.3\%) followed by PPH (6\%). The incidence of HELLP syndrome was $1.8 \%$ as opposed to the incidence of $2.2 \%$ in the study by MacGillivray I et al. ${ }^{13}$ Prematurity is the most common complication occurring in $30.9 \%$ of deliveries. Similar, findings were reported by Maikarnaz $\mathrm{P}$ et al, where incidence of prematurity were $17.99 \%$, $47.62 \%$ and $52.63 \%$ in mild preeclampsia, severe preeclampsia, and eclampsia respectively. ${ }^{14,15}$

\section{CONCLUSION}

From the above demographic and other data presented, it becomes evident that pregnancy induced hypertension is one of the major causes of admissions to antenatal wards apart from being a significant contribution towards 
maternal morbidity, mortality, and complications. Complications can affect all maternal systems including Central nervous system, renal system, and hematological systems. Apart from these, the fetus also faces the brunt of insult. Fetal complications include prematurity, low birth weight, stillbirths, intrauterine deaths, and intrauterine growth restrictions. However, such vast complications can be prevented by simple blood pressure monitoring and proper antenatal mother follow-up.

\section{Funding: No funding sources}

Conflict of interest: None declared

Ethical approval: The study was approved by the Institutional Ethics Committee

\section{REFERENCES}

1. Baker PN, Philip N, Johnson IR. The use of a handgrip test for predicting pregnancy-induced hypertension. Eur J Obstet Gynecol Reprod Biol. 1994;56(3):169-72.

2. Berg CJ, Chang J, Callaghan WM, Whitehead SJ. Pregnancy-related mortality in the United States, 1991-1997. Obstet Gynecol. 2003;101(2):289-96.

3. Bouthoorn SH, Gaillard R, Steegers EA, Hofman A, Jaddoe VW, van Lenthe FJ, et al. Ethnic differences in blood pressure and hypertensive complications during pregnancy: The generation R study. Hypert. 2012;60(1):198-205.

4. Cantwell R, Clutton-Brock T, Cooper G, Dawson A, Drife J, Garrod D, et al. Saving Mothers' Lives: Reviewing maternal deaths to make motherhood safer: 2006-2008. The Eighth Report of the Confidential Enquiries into Maternal Deaths in the United Kingdom. BJOG: Int J Obstet Gynaecol. 2011;118:1-203.

5. Chesley LC. Diagnosis of preeclampsia. Obstet Gynecol. 1985;65:423-5.

6. Chhabra S, Gandhi D. Prediction of pregnancyinduced hypertension/ pre-eclampsia by detecting microalbuminuria. J Obstet Gynecol India. 2002;52(1):56-60.

7. Cincotta RB, Brennecke SP. Family history of preeclampsia in primigravida. Int J Gynaecol Obstet. 1998;60:23-7.
8. James PR, Nelson-Piercy C. Management of hypertension before, during and after pregnancy. Heart. 2004;90:1499-504.

9. Jeffcoate, Scott JS. Some observations of placental Factor in pregnancy toxemia. Am J Obstet Gynecol. 1959;72:475-89.

10. Khan KS, Wojdyla D, Say L, Gülmezoglu AM, Van Look PF. WHO analysis of causes of maternal death: a systematic review. The Lancet. 2006;367(9516):1066-74.

11. Lamminpää R, Vehviläinen-Julkunen K, Gissler M, Heinonen S. Preeclampsia complicated by advanced maternal age: a registry-based study on primiparous women in Finland 1997-2008. BMC Preg Childbirth. 2012;12(1):47.

12. Levine RJ, Ewell MG, Hauth JC, Curet LB, Catalano PM, Morris CD, et al. Should the definition of preeclampsia include a rise in diastolic blood pressure of $\geq 15 \mathrm{mmHg}$ to a level $<90 \mathrm{mmHg}$ in association with proteinuria?. Am J Obstet Gynecol. 2000;183(4):787-92.

13. MacGillivray I. Some observations on the incidence of preeclampsia. J Obstet Gynaecol Br Common. 2005;65:536-9.

14. Magee LA, Helewa M, Moutquin JM, Von Dadelszen P. Hypertension guideline committee, strategic training initiative in research in the reproductive health sciences (STIRRHS) scholars: diagnosis, evaluation, and management of the hypertensive disorders of pregnancy. J Obstet Gynaecol Can. 2008;30(3 Suppl):S1-48.

15. Maikranz P, Holley JL, Parks JH, Lindheimer MD, Nakagawa Y, Coe FL. Gestational hypercalciuria causes pathological urine calcium oxalate supersaturations. Kidney Int. 1989;36(1):108-13.

Cite this article as: Shruthi S, Thenmozhi G.

Maternal and perinatal outcome in pregnant women with hypertensive disorders: a population-based study. Int J Reprod Contracept Obstet Gynecol 2020;9:194-9. 